DANWEN BAO, Ph.D. ${ }^{1}$

(Corresponding author)

E-mail: baodanwen@nuaa.edu.cn

XIAOLING ZHANG, Ph.D. ${ }^{2}$

E-mail: xiaoling.zhang@cityu.edu.hk

JIAYU GU, Master's Degree Candidate ${ }^{1}$

E-mail: 971220205@qq.com

${ }^{1}$ College of Civil Aviation

Nanjing University of Aeronautics and Astronautics

No. 169, Shengtai West Road, Jiangning District,

Nanjing 210016, China

2 Department of Public Policy

City University of Hong Kong

Tat Chee Avenue, Kowloon, Hong Kong
Traffic and Environment (Ecology)

Preliminary Communication

Submitted: 2 May 2017

Accepted: 5 Mar. 2018

\title{
EVALUATION METHOD FOR GREEN ECOLOGICAL AIRPORTS IN CHINA BASED ON COMBINATION WEIGHTING
}

\begin{abstract}
To scientifically and accurately evaluate the status of the development of green airports in China, evaluation methods of green, ecological airports are established in this paper. To address the shortcomings in subjective and objective weighting methods, we propose a combination weighting method based on Spearman's rank correlation coefficient and evaluation grades based on interval approximation. At the same time, by taking into account resource conservation, environmental friendliness, operation efficiency, and people-oriented service, we propose an evaluation index system and an interval number for each index. Lastly, the theory is applied to five large airports in different regions of China. Analysis of the evaluation results shows that Shanghai Pudong International Airport (PVG) and Guangzhou Baiyun International Airport (CAN) have the highest scores for the resource conservation and environmental friendliness indexes, thus indicating that the development of a green ecological airport is closely related to its passenger transportation scale and economic strength. All considered airports showed the need for upgrading public service facilities and constructing intelligent equipment. The method proposed in this paper is reasonable and reliable; therefore, it can provide guidance for the evaluation and construction of green, ecological airports.
\end{abstract}

\section{KEY WORDS}

ecological airport; evaluation index; combination weighting;

\section{INTRODUCTION}

Having experienced rapid development over many years, the civil aviation industry in China has witnessed a continued rise in energy consumption and increased environmental pressure. Statistics have shown that the total energy consumption of civil aviation accounts for $8 \%$ of that of the entire transportation industry, whereas energy consumption by airports accounts for approximately $3 \%$ of that of civil aviation [1]. The $13^{\text {th }}$ 5 -year plan issued by the Civil Aviation Administration of China (CAAC) in March 2017 clearly established the goals of constructing airports that have excellent environmental protection, conserve resources, operate efficiently, and establish people-oriented services. Therefore, the construction of green, ecological airports will be the direction of future development. Many researchers have explored the concept of green, ecological airports. In the early 1990s, researchers from China and other countries applied green building evaluation standards to airport terminals. Typical evaluation systems include the Building Research Establishment Environmental Assessment Method (BREEAM) proposed by the UK Building Research Establishment [2], the Green Building Challenge 2000 (GBD2000) established by Natural Resources Canada [3], and the Leadership in Energy and Environmental Design (LEED) Rating System in the United States of America [4]. The establishment of a green building evaluation system started later in China, and comprehensive evaluation standards such as the Assessment Standard for Green Building were established in 2006 [5]. Entering the $21^{\text {st }}$ century, researchers have started to focus on study of green airports and have come to believe that the construction of airports should focus on improvements in functionality and efficiency, including decreasing the life-cycle cost, obtaining financial subsidies from the government, and establishing a corporate citizen image. Li \& Liu believed that the connotation of a green airport should include selecting a site that satisfies sustainable development, ensures water supply and water usage efficiency, conserves and uses renewable energy, and provides for the protection of materials and resources [6, 7]. Chen \& Su proposed 
an evaluation index for green airports by primarily considering energy use and the generation of waste water, waste gas, noise, and solid waste [8]. Researchers in China have undertaken evaluation of green airports mostly from the perspectives of construction and management. Wang et al. considered not only the hard index of building but also the soft index of management [9]. Wu established an evaluation system based on resource conservation and usage and environmental protection [10].

The theories and practices mentioned above have laid out a good foundation for the present paper. However, deficiencies still exist, which are manifested in the following two ways. (1) There is a lack of comprehensive evaluation for functional regions, such as the area of the airfield and landside transportation; therefore, an evaluation index system that comprehensively accounts for energy savings, environmental protection, operations, and services has not been developed. (2) Existing studies emphasize the design of evaluation indexes. Because of the lack of evaluation standards that consider the actual situation of domestic airports and the lack of evaluation grading standards that can provide a baseline reference, the evaluation method is usually qualitative in nature.

Therefore, to establish a green airport evaluation system that is suitable for the actual circumstances of airports in China, the present paper establishes a green, ecological airport evaluation index system, as well as the evaluation criteria for each index. Evaluation methods based on rank correlation coefficient combination weighting and interval approximation are also established. In addition, the theory is used to evaluate five representative large airports in different regions of China.

\section{MATERIALS AND METHODOLOGY}

\subsection{Study area}

"The $13^{\text {th }}$ Five-Year Plan for Civil Aviation Development in China" issued in 2016 clearly states that green and sustainable development should be the target of airports with an annual passenger throughput of 10 million person-time. Large airports are the focus of green, ecological airport construction. Therefore, large airports with passenger throughputs greater than 10 million were chosen in this case study. At the same time, regional differences were also taken into account when selecting the samples, i.e., one typical airport in each region was selected: Shanghai Pudong International Airport (PVG), Guangzhou Baiyun International Airport (CAN), Ürümqi Diwopu International Airport (URC), Shenyang Taoxian International Airport (SHE), and Wuhan Tianhe International Airport (WUH).

\subsection{Data sources}

A literature review and expert analysis were used to obtain 3 types of data: (1) daily energy consumption of airports - for example, noise and the emission of waste, wastewater, and solid waste all come from the energy consumption data published on the website of each airport; (2) airport building characteristics - for example, the thermal performance of the enclosure structure, percentage of high-strength and high-durability materials, percentage of reused construction and demolition waste, and airport landside green ratio all come from assessment reports including the design report, environmental impact assessment reports and quality appraisal/accreditation reports; (3) level of airport management system - for example, indexes such as the emergency response capability and technical/ environmental management system were obtained from expert analysis. All data reflect the real situation in 2016.

\subsection{Evaluation method}

\section{Subjective weighting}

First, subjective weighting was given to the first-order, second-order, and third-order indexes of green, ecological airports after adequate consideration of the opinions of the experts in the industry.

\section{Objective weighting}

Let the scheme set $M$ and index set $N$ be:

$$
\begin{aligned}
& M=\left\{M_{1}, M_{2}, \ldots, M_{n}\right\} \\
& N=\left\{N_{1}, N_{2}, \ldots, N_{m}\right\}
\end{aligned}
$$

where $n$ is the number of decision schemes, and $m$ is the number of indexes in the scheme.

The decision matrix $X$, which is formed from the scheme set $M$ and index set $N$, is:

$$
X=\left(x_{i j}\right)_{n \cdot m}=\left(\begin{array}{ccc}
x_{11} & \cdots & x_{1 m} \\
\vdots & \ddots & \vdots \\
x_{n 1} & \cdots & x_{n m}
\end{array}\right)
$$

where $x_{i j}$ is the $j$-th index of the scheme $i$.

The normalization of the initial index values yields:

$y_{i j}=\frac{x_{i j}-x_{j}^{\min }}{x_{j}^{\max }-x_{j}^{\min }}$

Then, the decision matrix, $X$, is transformed to the normalized decision matrix $Y$ :

$$
Y=\left(y_{i j}\right)_{n \cdot m}=\left(\begin{array}{ccc}
y_{11} & \cdots & y_{1 m} \\
\vdots & \ddots & \vdots \\
y_{n 1} & \cdots & y_{n m}
\end{array}\right)
$$

where $y_{i j}$ is the normalized index value, and where $x_{j}^{\max }$ and $x_{j}^{\min }$ are the maximum and minimum, respectively, of the indexes in the scheme $j$. 
The weighting calculation equation using the minimum membership average weighted deviation method is as follows:

$w_{j}=\frac{\sum_{i=1}^{n} g_{j}-y_{i j}}{\sum_{j=1}^{m} \sum_{i=1}^{n} g_{j}-y_{i j}}$
$g_{j}=\max \left\{y_{1}, y_{2}, \ldots, y_{n j}\right\}$

where $w_{j}$ is the weighting of the $j$-th index.

The weighting calculation equations using the mean squared error method are as follows:

$w_{j}=\frac{\sigma_{j}}{\sum_{j=1}^{m} \sigma_{j}}$

$\sigma_{j}=\frac{1}{n} \sqrt{\sum_{i=1}^{n}\left(y_{i j}-P_{j}\right)^{2}}$

$P_{j}=\frac{1}{n} \sum_{i=1}^{n} y_{i j}$

\section{Combination weighting}

Step 1: Calculate the Spearman's rank correlation coefficient. Assuming there are $s$ types of weighting methods, the relevant weighting coefficient is as follows:

$\rho_{a k}=1-\frac{\sum_{j=1}^{m}\left(w_{a j}^{0}-w_{k j}^{0}\right)^{2}}{m(m-1)(m+1)}$

where $\rho_{a k}$ is the Spearman's rank correlation coefficient between the $a$-th weighting method and the $k$-th weighting method, and $w_{a j}^{0}$ is the weighting of the $j$-th index measured by the $a$-th method.

Step 2: Search for a method with the best consistency. First, find the maximum of the Spearman's rank correlation coefficient:

$\rho_{u v}=\max \left(\rho_{a k}\right)$

Compare the Spearman's rank correlation coefficient of the methods $u, v$ and other methods and choose the maximum. Assume the selected method is $u$, that is, $u$ is the weighting method with the highest consistency among all weighting methods; the Spearman's rank correlation coefficients of other methods and method $u$ form the correlation factor $\rho_{u}$ :

$\rho_{u}=\left(\rho_{u 1}, \rho_{u 2}, \ldots, \rho_{u s}\right)$

Step 3: Normalize pu to yield the weighting vector $W$ of the method $u$ :

$W=\left(w_{1}^{0}, w_{2}^{0}, \ldots, w_{s}^{0}\right)$ $w_{a} \frac{\rho_{u a}}{\sum_{a=1}^{s} \rho_{u a}}$

where $w_{a}^{0}$ is the weighting of method $a$.

Step 4: Calculate the comprehensive weighting of the indexes:

$$
\begin{aligned}
\theta & =\left(\theta_{1}, \theta_{2}, \ldots, \theta_{m}\right)=W \cdot W^{0}= \\
& =\left(w_{1}^{0}, w_{2}^{0}, \ldots, w_{s}^{0}\right) \cdot\left(\begin{array}{ccc}
w_{11}^{0} & \cdots & w_{1 m}^{0} \\
\vdots & \ddots & \vdots \\
w_{s 1}^{0} & \cdots & w_{s m}^{0}
\end{array}\right)
\end{aligned}
$$

where $W^{0}$ is the weight matrix of $m$ types of index by $s$ types of methods; $\theta$ is the index weight vector; $w_{a j}^{0}$ is the weighting of method $a$ for the $j$-th index; and $\theta_{j}$ is the comprehensive weighting for the $j$-th index.

Last, the multiplication of the comprehensive weight vector $\theta$ and the decision matrix $X$ gives rise to the evaluation score for the index $R$ :

$$
\begin{aligned}
R & =\left(r_{1}, r_{2}, \ldots, r_{n}\right)= \\
& =\left(\theta_{1}, \theta_{2}, \ldots, \theta_{m}\right) \cdot\left(\begin{array}{ccc}
x_{11} & \cdots & x_{1 m} \\
\vdots & \ddots & \vdots \\
x_{n 1} & \cdots & x_{n m}
\end{array}\right)^{T}
\end{aligned}
$$

$r=\frac{1}{n} \sum_{i=1}^{n} r_{i}$

where $r_{i}$ is the score of the scheme $i$.

\section{Interval approximation method}

Step 1: Determine the evaluation effect index system. There are three grades of evaluation indexes for the green ecological airports. The interval number was used grade by grade to approximate the decision model for evaluation. Ultimately, a comprehensive evaluation score was obtained.

Let the score set for the $m$ number of sub-indexes in an upper-level index be $\left\{\mathrm{O}_{1}, \mathrm{O}_{2}, \ldots, \mathrm{O}_{m}\right\}$ and each of the index evaluation grade sets be $\left\{Q_{1}, Q_{2}, \ldots, Q_{p}\right\}$, where $Q_{e}$ is the functional effect's grade. The functional effect evaluation standard is shown in Table 1. Assuming that each scheme value for the $j$-th index conforms to the normal distribution $\left[z_{e j}^{L}, z_{e j}^{U}\right]$ with a confidence interval of $95 \%$, the upper and lower limits of the classification of index $j$ are $z_{e j}^{L}$ and $z_{e j}^{U}$, respectively.

Step 2: Establish the decision matrix. Let the functional effect score set of the to-be-evaluated index $O$ be $\left\{\left[z_{01}^{L}, z_{01}^{U}\right],\left[z_{02}^{L}, z_{02}^{U}\right], \ldots,\left[z_{0 m}^{L}, z_{0 m}^{U}\right]\right\}$; the decision matrix of the index score is:

$\left.Z=\left(\begin{array}{ccc}{\left[z_{01}^{L}, z_{01}^{U}\right]} & \cdots[ & \left.z_{0 m}^{L}, z_{0 m}^{U}\right] \\ \vdots & \ddots & \vdots \\ {\left[z_{p 1}^{L}, z_{p 1}^{U}\right]} & \cdots & {\left[z_{p m}^{L}, z_{p m}^{U}\right]}\end{array}\right]\right) Q_{0}$

where $Q_{0}$ is the grade corresponding to the index $O$ awaiting evaluation.

Table 1 - Single index classification criteria

\begin{tabular}{|c||c|c|c|c|c||}
\hline \hline Index & $O_{1}$ & $\ldots$ & $O_{j}$ & $\ldots$ & $O_{m}$ \\
\hline Score & $z_{e 1}^{L} \sim z_{e 1}^{U}$ & $\ldots$ & $z_{e j}^{L} \sim z_{e j}^{U}$ & $\ldots$ & $z_{e m}^{L} \sim z_{e m}^{U}$ \\
\hline
\end{tabular}


Step 3: Establish the decision-evaluation matrix for the interval number. After the weight index $\theta$ is added to the decision matrix $Z$, the interval number decision-evaluation matrix $T$ is:

$$
\begin{aligned}
& T=\left(\begin{array}{ccc}
{\left[z_{01}^{L} \theta_{1}, z_{01}^{U} \theta_{1}\right]} & \cdots & {\left[z_{0 m}^{L} \theta_{m}, z_{0 m}^{U} \theta_{m}\right]} \\
\vdots & \ddots & \vdots \\
{\left[z_{p 1}^{L} \theta_{1}, z_{p 1}^{U} \theta_{1}\right]} & \cdots & {\left[z_{p m}^{L} \theta_{m}, z_{p m}^{U} \theta_{m}\right]}
\end{array}\right) \begin{array}{c}
Q_{0} \\
\vdots \\
Q_{p}
\end{array}= \\
& =\left(\begin{array}{ccc}
{\left[q_{01}^{L}, q_{01}^{U}\right]} & \cdots[ & {\left[q_{0 m}^{L}, q_{0 m}^{U}\right]} \\
\vdots & \ddots & \vdots \\
{\left[q_{p 1}^{L}, q_{p 1}^{U}\right]} & \cdots & {\left[q_{p m}^{L}, q_{p m}^{U}\right]}
\end{array}\right] Q_{Q_{p}}
\end{aligned}
$$

Step 4: Determine the evaluation grade. Calculate the distance between the evaluation scheme and each grade. The grade with the shortest distance is the evaluation grade for the scheme awaiting evaluation. The distance from $Q_{0}$ to $Q e$ is:

$$
\begin{aligned}
& d_{e}=\sqrt{d_{e 1}^{2}+d_{e 2}^{2}+\ldots d_{e m}^{2}} \\
& d_{e j}=\max \left\{\left|q_{0 j}^{L}-q_{e j}^{L}\right|,\left|q_{0 j}^{U}-q_{e j}^{U}\right|\right\}
\end{aligned}
$$

where $d_{e}$ is the distance from the to-be-evaluated index $O$ to the grade $e$.

\subsection{Construction of the evaluation index system}

\subsubsection{Source and basis of the indexes}

First, the reference standards included the Green Terminal Standard (MH/T5033-2017) [11], Assessment Standard for Green Building (GB/T50378-2014) [5], Standard for Energy Saving in Public Buildings (GB50189-2015) [12], Standard for Water-Saving Design in Civil Building (GB50555-2010) [13], Evaluation Standard for Green Construction of Buildings (GB/T50640-2010) [14], Code for the Master Planning of Civil Airports (MH5002-1999) [15], Standard for Construction of Civil Airport Projects (105-2008) [16], Guidelines for Energy-Efficiency Evaluation of Civil Airport Terminals (MH/T5112-2016) [17], Standards for Civil Transportation Airport Service Quality (MH/T5104-2013) [18], Technical Standards for the Airfield Areas of Civil Airports (MH/T5001-2013) [19], and Standard for the Design of Intelligent Buildings (GB50314-2015) [20]. Second, questionnaires and interviews were used to gather advice from experts in the civil aviation industry and managers/staff in airports for the addition, selection, and modification of indexes.

\subsubsection{Evaluation index system}

Based on the existing evaluation standards for green buildings and airports, the evaluation index system was preliminarily established by integrating the opinions of experts and personnel in the industry and by analyzing data and documents on the current status of the design, construction, operation, and management of domestic airports, as shown in Table 2. The corresponding evaluation standard is referenced to domestic norms [11-20].

\section{RESULTS}

\subsection{Evaluation process}

\subsubsection{Calculation of the weighting}

Take the evaluation of PVG as an example. First, the second-order indexes of energy saving were evaluated. Based on the scores assigned by the experts, the interval number of each third-order index in the energy-saving index was then calculated; a confidence interval of $95 \%$ was chosen, and the calculated results are shown in Table 3.

Each index was used as a third-order index in the combination weighting, thus comprising the energy-saving evaluation index set. Therefore, the decision matrix $X$ is:

$X=\left[\begin{array}{llll}91 & 80 & 90 & 81 \\ 90 & 80 & 91 & 84 \\ 93 & 80 & 89 & 80 \\ 90 & 82 & 90 & 82 \\ 94 & 82 & 90 & 79\end{array}\right]$

The normalization of the above indexes yields the matrix $Y$ :

$$
Y=\left[\begin{array}{llll}
0.25 & 0.00 & 0.50 & 0.40 \\
0.00 & 0.00 & 1.00 & 1.00 \\
0.75 & 0.00 & 0.00 & 0.20 \\
0.00 & 1.00 & 0.50 & 0.60 \\
1.00 & 1.00 & 0.50 & 0.00
\end{array}\right]
$$

The objective weight by minimum membership degree is $(0.266,0.266,0.220,0.248)$, the objective weight by mean square deviation method is $(0.261$, $0.315,0.203,0.221)$, and the subjective weight of the experts is $(0.28,0.21,0.32,0.19)$. According to the combination weighting method based on the Spearman's rank correlation coefficient, the comprehensive weight of the three indexes is $(0.27,0.26,0.25,0.22)$. Multiplying the comprehensive weight vector by the decision matrix, one can obtain the evaluation matrix, which is $(85.7,86.3,85.8,86.1,86.6)$, and the score of the energy saving evaluation index is 86.1. All the scores of second-order indexes of PVG in Table 3 can be calculated using the same method.

\subsubsection{Evaluation of each index}

The interval number approximation method was used for the evaluation of each index. The score interval of the energy-saving index for the design of buildings is [90.2, 93.0], which has a distance of $d_{1}$ to the excellent grade of $d_{1}=\sqrt{(90.2-85)^{2}+(93-100)^{2}}=8.72$ 
Table 2 - Evaluation index system

\begin{tabular}{|c|c|c|}
\hline First-order index & Second-order index & Third-order index \\
\hline \multirow{13}{*}{$\begin{array}{l}\text { Resource } \\
\text { conservation }\left(P_{1}\right)\end{array}$} & \multirow{4}{*}{ Energy saving $\left(P_{11}\right)$} & Energy saving index for the design of buildings $\left(q_{1}\right)$ \\
\hline & & Thermal performance index for the enclosing structure $\left(q_{2}\right)$ \\
\hline & & Decrease in energy consumption index $\left(q_{3}\right)$ \\
\hline & & Index for the comprehensive use of energy $\left(q_{4}\right)$ \\
\hline & \multirow{3}{*}{ Land saving $\left(P_{12}\right)$} & Per capita area at peak hour $\left(q_{5}\right)$ \\
\hline & & Distance between neighboring gates per unit area $\left(q_{6}\right)$ \\
\hline & & Design index for the intensification of functional zones $\left(q_{7}\right)$ \\
\hline & \multirow{3}{*}{ Water saving $\left(P_{13}\right)$} & Water quota from water saving $\left(q_{8}\right)$ \\
\hline & & Percentage of water-saving technology or measures used $\left(q_{9}\right)$ \\
\hline & & Usage efficiency of non-traditional water sources $\left(q_{10}\right)$ \\
\hline & \multirow{3}{*}{ Material saving $\left(P_{14}\right)$} & Percentage of high-strength and high-durability materials used $\left(q_{11}\right)$ \\
\hline & & Percentage of waste and demolished materials used $\left(q_{12}\right)$ \\
\hline & & Percentage of renewable materials used $\left(q_{13}\right)$ \\
\hline \multirow{7}{*}{$\begin{array}{l}\text { Environmental } \\
\text { friendliness }\left(P_{2}\right)\end{array}$} & \multirow{4}{*}{$\begin{array}{l}\text { Environmental control } \\
\left(P_{21}\right)\end{array}$} & Noise $\left(q_{14}\right)$ \\
\hline & & Air quality $\left(q_{15}\right)$ \\
\hline & & Water $\left(q_{16}\right)$ \\
\hline & & Solid waste $\left(q_{17}\right)$ \\
\hline & \multirow{3}{*}{$\begin{array}{l}\text { Ecological friendliness } \\
\left(P_{22}\right)\end{array}$} & Index for ecological resource conservation $\left(q_{18}\right)$ \\
\hline & & Landside green coverage $\left(q_{19}\right)$ \\
\hline & & Prevention and effectiveness of bird strikes $\left(q_{20}\right)$ \\
\hline \multirow{6}{*}{$\begin{array}{l}\text { Efficiency of } \\
\text { operations }\left(P_{3}\right)\end{array}$} & \multirow{3}{*}{$\begin{array}{l}\text { Operational efficiency } \\
\left(P_{31}\right)\end{array}$} & Flight on-time rate $\left(q_{21}\right)$ \\
\hline & & Average flight delay time $\left(q_{22}\right)$ \\
\hline & & Emergency response capability index $\left(q_{23}\right)$ \\
\hline & \multirow{3}{*}{$\begin{array}{l}\text { Management system } \\
\left(P_{32}\right)\end{array}$} & Management system certification $\left(q_{24}\right)$ \\
\hline & & Technical management system $\left(q_{25}\right)$ \\
\hline & & Environmental management system $\left(q_{26}\right)$ \\
\hline \multirow{6}{*}{$\begin{array}{l}\text { People-oriented } \\
\text { service }\left(P_{4}\right)\end{array}$} & \multirow{3}{*}{$\begin{array}{l}\text { Service convenience } \\
\left(P_{41}\right)\end{array}$} & Speed and convenience of processes $\left(q_{27}\right)$ \\
\hline & & Standardization of the guidance system $\left(q_{28}\right)$ \\
\hline & & Standardization of the public service facilities $\left(q_{29}\right)$ \\
\hline & \multirow{3}{*}{$\begin{array}{l}\text { Service intelligence } \\
\left(P_{42}\right)\end{array}$} & Percentage of self-service stations at the facility $\left(q_{30}\right)$ \\
\hline & & Wireless network $\left(q_{31}\right)$ \\
\hline & & Application of intelligent surveillance technology $\left(q_{32}\right)$ \\
\hline
\end{tabular}

Table 3 - Interval number of each index of energy saving

\begin{tabular}{||l|c|c||}
\hline \multicolumn{1}{|c|}{ Index } & Average value & Interval number \\
\hline \hline Energy saving index for the design of buildings & 91.6 & $90.2 \sim 93.0$ \\
\hline Thermal performance index for the enclosing structure & 80.8 & $80.2 \sim 81.4$ \\
\hline Decrease in energy consumption index & 90.0 & $89.4 \sim 90.6$ \\
\hline Index for the comprehensive use of energy & 81.2 & $79.3 \sim 83.1$ \\
\hline
\end{tabular}

Table 4 - Summary of the airport evaluation results

\begin{tabular}{||l||c|c|c|c|c||}
\hline Airport name & PVG & CAN & URC & SHE & WUH \\
\hline Evaluation score & 80.4 & 85.1 & 70.1 & 76.9 & 83.8 \\
\hline Evaluation grade & Good & Excellent & Average & Good & Good \\
\hline
\end{tabular}


and has a distance of $d_{2}$ to the good grade of $d_{2}=\sqrt{(90.2-70)^{2}+(93-85)^{2}}=21.7$. Since $d_{1}<d_{2}$, the grade of the energy saving index for the design of buildings is excellent.

Similarly, all third-order index evaluation grades can be obtained for PVG.

\subsubsection{Comprehensive evaluation}

Using the evaluation of the energy-saving index as an example, the aggregation of the decision matrix and weight vector yields the interval number decision matrix:

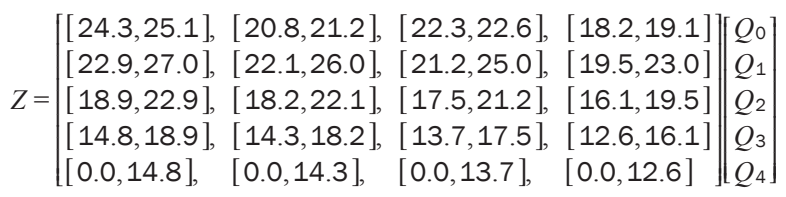

The calculated distances from the energy index set to the excellent, good, average, and poor grades are $6.90,7.96,13.2$, and 43.0, respectively. According to the evaluation principle, the energy-saving evaluation grade is excellent because $d_{1}$ is the smallest of the calculated results, and the grade corresponding to $Q_{1}$ is excellent.

Based on the same method, the grades of all second-order and first-order indexes can be obtained. Based on the evaluation principle, the distances from the first-order indexes to the excellent, good, average, and poor grades are calculated. Because the minimum $d_{2}$ is 4.55 and the grade corresponding to $Q_{2}$ is good, the green ecological evaluation for PVG is good.

\subsection{Evaluation results}

The various grade indexes of the remaining 4 airports were evaluated using the aforementioned calculation process. The evaluation results are shown in Table 4.

As shown in the evaluation results for the resource conservation index (Figure 1), PVG and CAN had the highest scores with excellent evaluation grades. This is because the concept of environmental protection was fully implemented in the new construction of terminal buildings in 2017 and 2015 by the two airports, respectively. Various measures, including the addition of glass curtain walls, the use of double-layered glass, chilled-water thermal storage, and rainwater recycling systems, were adopted to decrease energy consumption, thus effectively achieving energy-saving goals.

The environmental friendliness index evaluation results (Figure 2) show that the ecological friendliness index evaluation results varied greatly. CAN and WUH scored the highest. These findings can be attributed to the modification and expansion projects of the two airports, wherein large amounts of vegetation were planted. This was particularly true for the T3 terminal of WUH because of its addition of various ecological

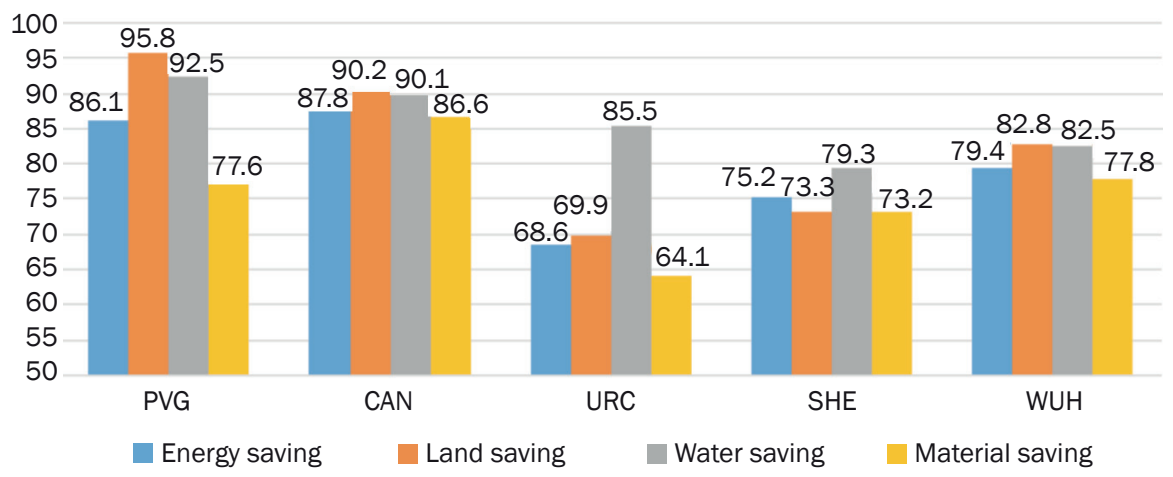

Figure 1 - Comparison of each airport's second-index scores of resource conservation

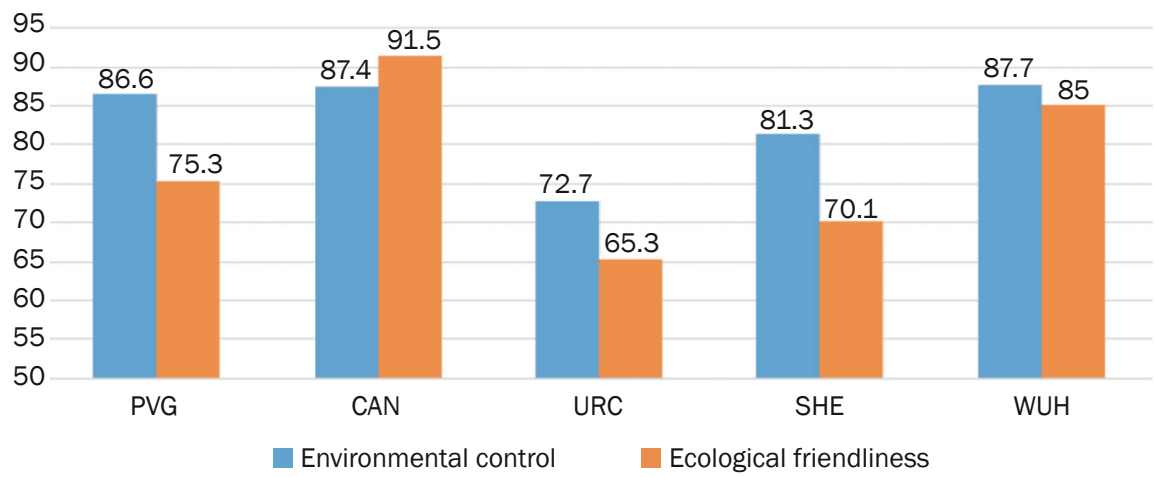

Figure 2 - Comparison of each airport's second-index scores of environmental friendliness 


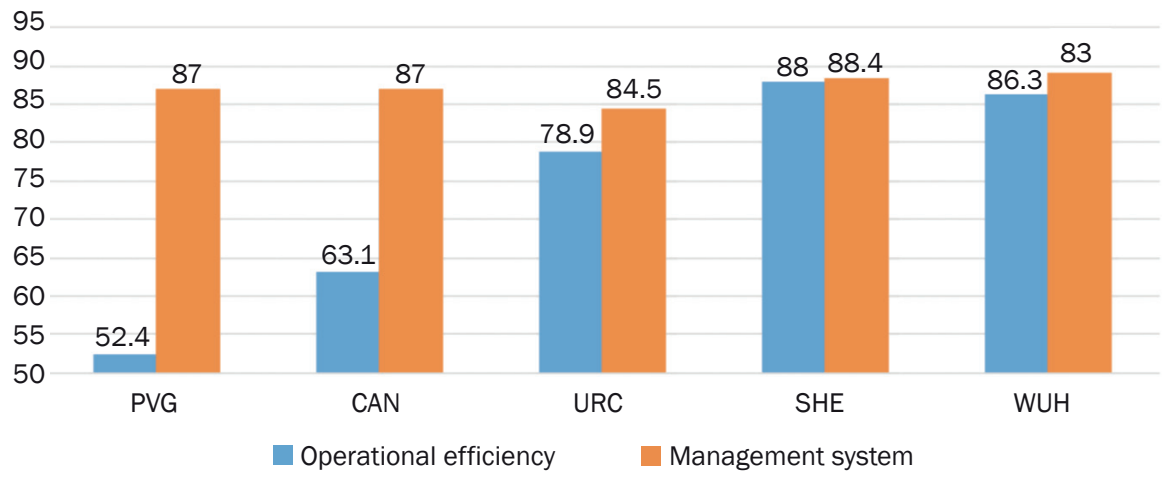

Figure 3 - Comparison of each airport's second-index scores of efficiency of operations

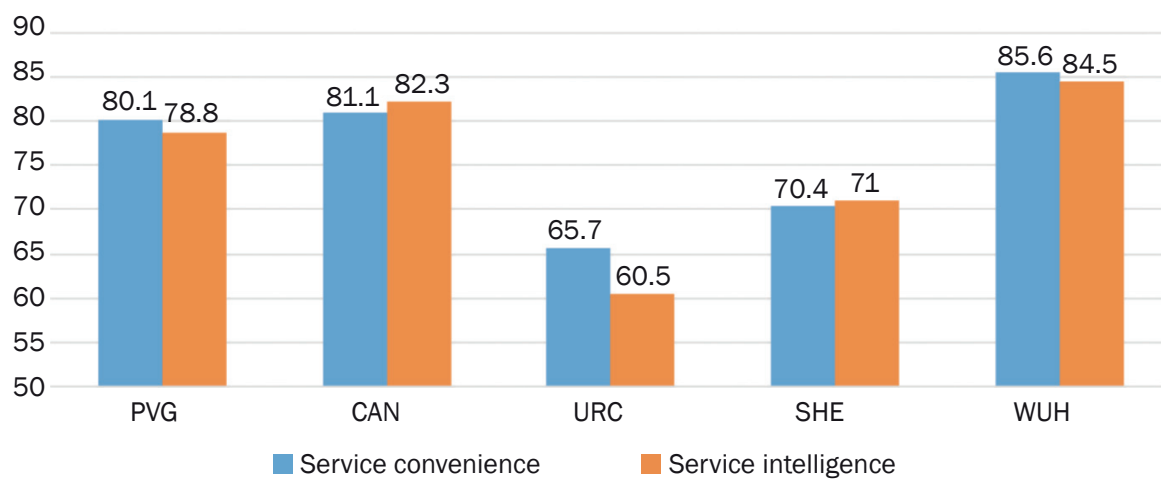

Figure 4 - Comparison of each airport's second-index scores of people-oriented service

zones, including flowerbeds, bonsai, and small gardens. Consequently, its green coverage exceeds $40 \%$, a much higher rate than at similar domestic airports. Thus, it has become a model for the construction of ecological airports.

The operational efficiency index evaluation result (Figure 3) shows that operational efficiency varied significantly among the five airports. PVG and CAN had very low operational efficiency. Between these two, the on-time rate of flights for PVG was only $52.4 \%$, and its average delay time was 48 minutes. Therefore, its operational efficiency was the lowest among the 5 airports. The main reason for this is that the capacity of the existing two terminals has already reached saturation.

The people-oriented service index evaluation result (Figure 4) shows that the evaluation grade was below good for all five airports, indicating that the airports do not provide satisfactory convenient and intelligent services. Investigations show that no self-directed security check-in, self-check-in, or self-directed baggage check-in have been set up in the five airports. The percentage of passengers using kiosks is less than $20 \%$. Domestic airports still need to strengthen their public service facilities by upgrading and developing intelligent equipment.

\section{DISCUSSION}

\subsection{Validity of methods}

The subjective and objective combination weighting method proposed in the paper can adequately integrate subjective and objective information. The determination of the weighting of the method using Spearman's rank correlation coefficient is more objective and scientific; furthermore, it can reflect the decision-makers' preference of each weighting method. In addition, it is simple and convenient to calculate. Therefore, this method has a more universal applicability in the determination of weighting of evaluation indexes. However, how does one prove that the results obtained from the combination weighting are valid? Traditionally, the Spearman's rank correlation coefficients of the combination weighting method $s$ and the original $q$ types of weighting methods $\rho_{i s}(i=1, \ldots, q)$ were calculated. The means of those coefficients reflect the average correlation between the combination weighting method $s$ and the original $q$ types of weighting methods. The higher the index is, the more reasonable the corresponding combination weighting method $s$ will be. The aforementioned method was used to test the validity of the results obtained from the combination weighting method. Using the weighting of the 
first-order indexes as an example, the weighting results obtained from the four aforementioned methods are listed in Table 5: $\rho_{s}=\frac{1}{q} \sum_{i=1}^{q} \rho_{i s}$

The weighting vectors in Table 5 were transformed to weighting ranking vectors, and the results are shown in Table 6.

The weighting ranking difference between any of the two weighting methods can be calculated based on Equation 23, and the results are shown in Table 7.

$d_{i}=x_{i}-y_{i}$

where $d_{i}$ is the weighting ranking difference of the index $i$ determined from different weighting methods, $x_{i}$ is the weighting ranking of the index $i$ from the $x$-th weighting method, and $y_{i}$ is the weighting ranking of the index $i$ from the $y$-th weighting method.

Based on Equation 24, the Spearman's rank correlation coefficient of any two weighting methods can be calculated. At the same time, the mean of the rank correlation coefficients from each method can be calculated. The results are shown in Table 8.

$\rho_{p q}=1-\frac{6 \sum_{i=1}^{n} d_{i}^{2}}{n\left(n^{2}-1\right)}$

where $\rho_{p q}$ indicates the Spearman's rank correlation coefficient of weighting methods $p$ and $q$, and $n$ indicates the quantity of the evaluation indexes.

It can be seen from the mean of the correlation coefficients of the 4 methods that method $4>$ method $2>$ method $1>$ method 3 , which shows that the results obtained from the combination weighting method were the most reasonable, followed by the mean squared error and the minimum membership degree methods. The results obtained from the subjective weighting method were the least reasonable. Similar
Table 5 - Weighting of the first-order indexes determined by the four weighting methods

\begin{tabular}{|c|c|c|c|c||}
\hline $\begin{array}{c}\text { Indexes } \\
\text { Methods }\end{array}$ & $P_{1}$ & $P_{2}$ & $P_{3}$ & $P_{4}$ \\
\hline \hline 1 & 0.266 & 0.271 & 0.215 & 0.248 \\
\hline 2 & 0.261 & 0.315 & 0.221 & 0.203 \\
\hline 3 & 0.28 & 0.21 & 0.32 & 0.19 \\
\hline 4 & 0.27 & 0.26 & 0.25 & 0.22 \\
\hline
\end{tabular}

Note: Method 1: Minimum membership degree; Method 2:

Mean squared error; Method 3: Subjective weighting; Method 4: Combination weighting

Table 6 - Ranking of weighting of the first-order indexes determined by the four weighting methods

\begin{tabular}{|c|c|c|c|c||}
\hline $\begin{array}{r}\text { Indexes } \\
\text { Methods }\end{array}$ & $P_{1}$ & $P_{2}$ & $P_{3}$ & $P_{4}$ \\
\hline \hline 1 & 2 & 1 & 4 & 3 \\
\hline 2 & 2 & 1 & 3 & 4 \\
\hline 3 & 2 & 3 & 1 & 4 \\
\hline 4 & 1 & 2 & 3 & 4 \\
\hline
\end{tabular}

results were obtained from the validity analysis of the weighting of the second-order and third-order indexes. The difference mainly comes from the different ways of calculating the weighting coefficient between the method used in this paper and the traditional methods. In the traditional methods, the degree of consistency of the mean of each weighting method is used as the weighting coefficient. Whereas in this paper, the weighting method with the highest relative consistency was the goal. Then, the Spearman's rank correlation coefficients of all the methods, including this method, were used as the weighting. This method more comprehensively uses the information provided by the

Table 7 - Weighting ranking difference of the indexes obtained from the four weighting methods

\begin{tabular}{||c|c|c|c|c|c|c||}
\hline & $\begin{array}{c}\text { Method 1/ } \\
\text { Method 2 }\end{array}$ & $\begin{array}{c}\text { Method 1/ } \\
\text { Method 3 }\end{array}$ & $\begin{array}{c}\text { Method 1/ } \\
\text { Method 4 }\end{array}$ & $\begin{array}{c}\text { Method 2 / } \\
\text { Method 3 }\end{array}$ & $\begin{array}{c}\text { Method 2 / } \\
\text { Method 4 }\end{array}$ & $\begin{array}{c}\text { Method 3 / } \\
\text { Method 4 }\end{array}$ \\
\hline \hline$P_{1}$ & 0 & 0 & 1 & 0 & 1 & 1 \\
\hline$P_{2}$ & 0 & -2 & -1 & -2 & -1 & 1 \\
\hline$P_{3}$ & 1 & 3 & 1 & 2 & 0 & -2 \\
\hline$P_{4}$ & -1 & -1 & -1 & 0 & 0 & 0 \\
\hline
\end{tabular}

Table 8 - Spearman's correlation coefficient of each weighting method

\begin{tabular}{||c|c|r|r|r|c||}
\hline \hline Evaluation method & Method 1 & Method 2 & Method 3 & Method 4 & Mean \\
\hline \hline Method 1 & 1.000 & 0.873 & 0.763 & 0.865 & 0.875 \\
\hline Method 2 & 0.873 & 1.000 & 0.782 & 0.892 & 0.886 \\
\hline Method 3 & 0.763 & 0.782 & 1.000 & 0.801 & 0.836 \\
\hline Method 4 & 0.865 & 0.892 & 0.801 & 1.000 & 0.890 \\
\hline
\end{tabular}


rank correlation coefficient matrix and more accurately reflects the difference of each weighting method. Therefore, the results are more valid and feasible.

\subsection{Advantages and disadvantages of methods}

The combination weighting method that is based on the Spearman's rank correlation coefficient not only reflects the subjective understanding of each index by experts but also retains the raw information of data. Therefore, this method combines the advantages of subjective and objective weighting methods, exhibits excellent effectiveness in evaluation cases, and can be applied to the comprehensive evaluation of green, ecological development levels in other areas. The interval approximation method places more emphasis on the representation of indexes and accuracy of an interval division. The selection of evaluation indexes is mainly based on expert analysis and also considers the standards and status quo of domestic airports. The evaluation index system based on resource conservation, environmental friendliness, operation efficiency, and people-oriented service matches closely with the development focus of domestic airports. Moreover, the weighting and interval estimate can eliminate subjectivity in the indexes. The evaluation results of the 5 large airports agree with real situations, suggesting that index selection and interval division have high application value.

However, it is worth noting that in the evaluation of airports in different regions, the local ecosystem has to be reassessed, the key impact factors on green airports have to be determined, and the evaluation indexes need to be adjusted to adapt to the actual local situation. For example, for evaluation of airports in coastal areas, the relevant indexes, such as water resources protection and water use efficiency, have to be taken into account.

\section{CONCLUSIONS}

In this paper, a green, ecological airport evaluation index system that comprises four first-grade indexes, 10 second-grade indexes and 32 third-grade indexes was constructed, and an evaluation standard for each index was established. Then, we established the evaluation index combination weighting method based on Spearman's rank correlation coefficient and designed a process to evaluate each third-grade index and carry out a comprehensive evaluation of the second-grade and first-grade indexes based on the interval approximation method. The evaluation scores and grades for the green, ecological airports were then obtained. Finally, the evaluation index system was used to evaluate five typical large domestic airports. The evaluation results showed that among the five airports CAN received the highest evaluation grade, followed by WUH, PVG, and SHE, while URC received the lowest evaluation grade.

The method of combining normative with empirical research is presented in this paper. The green eco-type airport evaluation index is closely integrated with the development of a domestic airport. For the first time, a systematic and comprehensive evaluation index system is established to further improve the research of green airport theory. At the same time, this index provides a guiding principle for China's green ecological airport evaluation and construction goal.

\section{ACKNOWLEDGEMENT}

This research was sponsored by the National Natural Science Foundation of China (Grant No. 51508274) and the Natural Science Foundation of Jiangsu Province (BK20140821).

\author{
包丹文, 讲师 ${ }^{1}$ \\ (通讯作者) \\ E-mail: baodanwen@nuaa.edu.cn \\ 张晓玲, 副教授 2 \\ E-mail: xiaoling.zhang@cityu.edu.hk \\ 顾佳羽, 硕士研究生 ${ }^{1}$ \\ E-mail:971220205@qq.com \\ 1 南京航空航天大学民航学院, \\ 江苏省南京市胜太西路169号, 210016 \\ 2 香港城市大学公共管理学院, \\ 香港特别行政区九龙达之路
}

\section{基于组合赋权的中国绿色机场评价方法}

\section{摘要:}

为了科学准确地评价中国绿色机场发展状况, 本文建 立了绿色生态型机场评价方法, 针对现有主观赋权法和客 观赋权法的不足, 提出了基于Spearman等级系数的组合 赋权方法，以及基于区间逼近法的评价等级确定方法; 同 时从资源节约、环境友好、运行高效和人性化服务四方面 提出了绿色生态型机场评价指标体系及指标区间, 并将理 论方法用于中国不同区域五座大型机场评价过程中。分析 结果显示，在资源节约和环境友好两项指标上，上海浦东 和广州白云机场的评分明显高于其它机场, 反映出绿色生 态型机场的发展程度与客运规模、经济实力密切相关; 在 人性化服务指标上, 各机场的得分均在85分以下，在公共 服务设施升级改造以及智能化设备建设方面需要加强。本 文提出的方法合理可靠, 对绿色生态型机场的评价和建设 具有一定的指导意义。

\section{关键词:}

生态型机场; 评价指标; 组合赋权

\section{REFERENCES}

[1] Xu J-K, Zhang W, Sun S-M. Brief analysis of energy consumption in domestic civil airports. Airport Construction. 2011;(2): 3-4.

[2] He X-Y. Green building evaluation system and appli- 
cation. 2008 World Forum of the Yangtze River Delta World Standard Day. 2008. p. 62-64.

[3] Ouyang SC. Introduction of U.S. green building evaluation system. Building Science. 2008;8(24): 32-34.

[4] Tsinghua University Building Energy Conservation Research Center. Research Report on Annual Development of China 's Building Energy Efficiency. Beijing: China Architecture \& Building Press; 2007.

[5] GB/T 50378-2014. Assessment Standard for Green Building. Beijing: China Architecture \& Building Press; 2014.

[6] Ni HY. The "green" pioneer - Boston's Logan International Airport. Air Transport \& Business. 2009;(13): 39-40.

[7] Liu M. Saving, environmental, science, technology and humanity - My opinion on building green airport. Creation. 2009;6(15): 68-73.

[8] Chen W-C, Su B-Y. Green Kunming new airport field road engineering design. Airport Construction. 2011;(2): 34-37.

[9] Wang X, SUN S-L. Research on green airport evaluation index system. Journal of Civil Aviation University of China. 2014;32(1): 83-87.

[10] Wu C. Green Airport Evaluation System Research Based on Sustainable Development. PhD thesis. Beijing: Beijing Forestry University; 2013.

[11] MH/T 5033-2017. Green Terminal Standard. Beijing:
China Civil Aviation Press; 2017.

[12] GB 50189-2015. Standard for Energy Saving in Public Buildings. Beijing: China Architecture \& Building Press; 2015.

[13] GB 50555-2010. Standard for Water-Saving Design in Civil Building. Beijing: China Architecture \& Building Press; 2010.

[14] GB/T 50640-2010. Evaluation Standard for Green Construction of Buildings. Beijing: China Planning Press; 2011.

[15] MH 5002-1999. Code for the Master Planning of Civil Airports. Beijing: China Planning Press; 2011.

[16] Construction Standard 105-2008. Standard for Construction of Civil Airport Projects. Beijing: China Planning Press; 2008.

[17] $\mathrm{MH} / \mathrm{T}$ 5112-2016. Guidelines for Energy-Efficiency Evaluation of Civil Airport Terminals. Beijing; China Civil Aviation Press; 2016.

[18] MH/T 5104-2013. Standards for Civil Transportation Airport Service Quality. Beijing; China Civil Aviation Press; 2013.

[19] MH/T 5001-2013. Technical Standards for the Airfield Areas of Civil Airports. Beijing; China Civil Aviation Press; 2013.

[20] GB 50314-2015. Standard for the Design of Intelligent Buildings. Beijing: China Planning Press; 2015. 